\title{
Desalination of porous building materials by electrokinetics: an NMR study
}

\author{
Kashif Kamran · Leo Pel · Alison Sawdy • \\ Henk Huinink $\cdot$ Klaas Kopinga
}

Received: 25 February 2011/Accepted: 27 July 2011/Published online: 11 August 2011

(C) The Author(s) 2011. This article is published with open access at Springerlink.com

\begin{abstract}
This article presents the first non destructive measurements of salt ions transport through fired-clay brick during electrokinetic desalination using nuclear magnetic resonance technique. The effect of the strength of an applied electric field on the migration of salt ions is examined by varying the electrical potential gradients from $0.75-2 \mathrm{~V} \mathrm{~cm}^{-1}$ across the specimens. The measurements show that for electrokinetic to exceed ion transport by diffusion a minimum level of applied voltage is necessary. Below this threshold salt transport by diffusion is dominant over electromigration. The effect of advection on the salt transport is studied by introducing a hydraulic gradient across the specimen. The results show that advection is a major transport process in the materials studied. To assess the relative magnitude of the various active transport processes during electrokinetic desalination, a scale analysis on the basis of dimensionless numbers is presented. The value of these numbers determines which transport mechanism will dominate the desalination process in a given sample length and time scale.
\end{abstract}

K. Kamran · L. Pel ( $₫) \cdot$ A. Sawdy · H. Huinink ·

K. Kopinga

Transport in Permeable Media, Department of Applied

Physics, Eindhoven University of Technology,

P.O. Box 513, 5600 MB Eindhoven, The Netherlands e-mail: 1.pel@tue.nl

K. Kamran

e-mail:k.kamran@tue.nl
Keywords Fired-clay brick · Diffusion - Advection · Electromigration $\cdot$ Nuclear magnetic resonance

\section{Introduction}

The deterioration of porous building materials and structures by the crystallization of water soluble salts is a well known phenomenon. The threats posed by salts to porous materials can be minimized either by controlling the environment or by removing the salts from the zone of deterioration. In the case of porous building materials salt extraction is typically accomplished by dry removal of the salt efflorescence and/ or aqueous methods-a common example of which being the use of poultices [1-3] to reduce salt content of the affected object. The extraction efficiency of a poultice is largely limited by the permeability and pore size distribution of both the poultice and the substrate $[4,5]$. Since the pore size distribution of a poultice can vary with its moisture content mainly due to its shrinkage during drying [5], it is difficult to tailor the pore size distribution of a poultice precisely to those required for optimum salt extraction efficiency. Also, the effective depth of salt extraction achieved using poultices in the case of building materials is often low, e.g. for fired-clay brick it is of the order of $20 \mathrm{~mm}$ [2]. Diurnal fluctuations in temperature and relative humidity are additional 
factors that can significantly affect the performance of a poultice [2]. It has been proposed that the limitations posed by poultices can be overcome by using electrokinetics as an alternative desalination method for brick masonry [6].

The electrokinetic method aims to remove ionic species from the zone of deterioration by an externally applied electric field. Although the electrokinetic technique has already been used to decontaminate soil [7] and concrete [8], its application in the desalination and dehumidification of masonry bricks and walls is a recent topic [6, 9-12]. During the electrokinetic desalination of masonry bricks, electromigration of salt ions is considered the dominant transport mechanism and the contribution of both diffusion and advection transport processes is usually neglected. In this study the effects of both diffusion and advection in addition to electromigration on the transport of salt ions through fired-clay bricks under an applied electric field are also considered.

Until now, the effect of electrokinetic desalination has been investigated using destructive methods. These methods are limited by their inability to measure variations in moisture and salt content in porous media during the salt extraction process. Moreover, the spatial resolution is restricted (being generally in the order of $10 \mathrm{~mm}$ ). Consequently, for this study non destructive measurements were performed during the electrokinetic desalination of building materials by using Nuclear magnetic resonance (NMR). It has been shown that NMR is a powerful technique for measuring the combined transport of moisture and $\mathrm{Na}$ ions in the building materials [13].

The objective of this work is to measure the contribution of diffusion, advection and electromigration to the overall salt transport under the influence of concentration, hydraulic and potential gradients respectively.

\section{Transport processes during electrokinetic desalination}

During electrokinetic desalination an applied electric field is used to mobilize salt ions from the depth of the porous material towards its surface. The removal of salt ions from the material's surface is then typically accomplished using aqueous poulticing methods. For this purpose during electrokinetic desalination poultices in the form of wet sorbent materials (e.g. sponges, clays etc.) are applied to the surface of the porous material together with the electrodes. However, the migration of salt ions towards the surface of the porous material and the applied poultice establish a concentration gradient within the material, and thereby can induce ion diffusion. Moreover, salt can also be transported by hydraulic gradients, caused by any difference in water level across the specimen. Finally, evaporative drying of the initially wet sorbent materials can also result in salt transport due to capillary advection.

A brief description of each of the transport processes (diffusion, advection, electromigration), in saturated porous media, relevant to this study is given below.

\subsection{Diffusion}

The transport of ions under the influence of a concentration gradient is known as diffusion. The flux of dissolved ions in free solutions can be described by the Fick's first law (see e.g. [14]):

$J_{\mathrm{d}}=D \frac{\partial C}{\partial x}$

where $J_{\mathrm{d}}\left(\mathrm{mol} \mathrm{m} \mathrm{m}^{-2} \mathrm{~s}^{-1}\right)$ is the flux of ions due to diffusion, $C\left(\mathrm{~mol} \mathrm{l}^{-1}\right)$ is the molar concentration, $D\left(\mathrm{~m}^{2} \mathrm{~s}^{-1}\right)$ is diffusion coefficient of ionic species and $x(\mathrm{~m})$ is the distance.

In porous materials the salt ions cannot diffuse freely and their diffusion rates are restricted by the porosity and tortuosity of the material. In addition, the chemical or electrical interaction of the material with the pore solution can also affect the diffusion rates. For non reactive porous materials the diffusion can be described by:

$J_{\mathrm{d}}=D_{\text {eff }} \frac{\partial C}{\partial x}$,

where $D_{\text {eff }}\left(\mathrm{m}^{2} \mathrm{~s}^{-1}\right)$ is the effective diffusion coefficient for a given non reactive porous material. For a porous material this effective diffusion coefficient is given by:

$D_{\text {eff }}=\phi T^{*} D$,

where $\phi\left(\mathrm{m}^{3} \mathrm{~m}^{-3}\right)$ is the porosity and $T^{*}$ is the tortuosity of the porous material. For many porous 
building materials, the diffusion coefficient is in the order of $0.1-1 \times 10^{-9} \mathrm{~m}^{2} \mathrm{~s}^{-1}$ [15].

\subsection{Advection}

In porous media advection refers to the transport of salt ions under the influence of a pressure gradient. The volumetric flux or Darcy velocity $v_{\mathrm{h}}\left(\mathrm{m} \mathrm{s}^{-1}\right)$ of a fluid through a porous medium due to a hydraulic gradient is given by Darcy's law (see e.g. [16]:

$v_{\mathrm{h}}=\frac{k}{\eta} \frac{\partial P}{\partial x}$

where $k\left(\mathrm{~m}^{2}\right)$ is the intrinsic permeability of the porous material, $P(\mathrm{~Pa})$ is the pressure across the porous material, and $\eta(\mathrm{Pa} \mathrm{s})$ is the dynamic viscosity of the fluid.

If we neglect hydraulic dispersion effects, the flux of salt ions contained within the pore fluid i.e. the movement of solute through a porous material due to a hydraulic gradient is given by:

$J_{\mathrm{h}}=C v_{\mathrm{h}}$,

where $J_{\mathrm{h}}\left(\mathrm{mol} \mathrm{m} \mathrm{m}^{-2} \mathrm{~s}^{-1}\right)$ is the flux of ions through the porous material and $C\left(\mathrm{~mol} \mathrm{l}^{-1}\right)$ is the molar concentration of ions in the pore solution. The permeability of clay bricks lies in the region of $10^{-12}-10^{-16} \mathrm{~m}^{2}[16,17]$.

\subsection{Electromigration}

When a potential difference is applied across an electrolytic solution the movement of salt ions induced in response to the electric field is known as electromigration. During electromigration the flux of salt ions through bulk solution is given by Atkins and de Paula [14]:

$J_{\mathrm{m}}=\mu C \frac{\partial V}{\partial x}$,

where $J_{\mathrm{m}}\left(\mathrm{mol} \mathrm{m} \mathrm{m}^{-2} \mathrm{~s}^{-1}\right)$ is the flux of salt ions due to electromigration, $\mu\left(\mathrm{m}^{2} \mathrm{~s}^{-1} \mathrm{~V}^{-1}\right)$ is the mobility of ions in the electrolyte solution, $C\left(\mathrm{~mol} \mathrm{l}^{-1}\right)$ is the molar concentration, $V(\mathrm{~V})$ is the applied voltage across the salt solution, and $x(\mathrm{~m})$ is the distance between electrodes.

Contrary to the case in bulk solutions, aqueous ions in porous materials are not able to move directly to the corresponding electrode by the shortest route. Instead, their movement is restricted by the porosity and tortuosity of the material. Hence, for a porous material the electromigration can be described by:

$J_{\mathrm{m}}=\mu_{\mathrm{eff}} C \frac{\partial V}{\partial x}$,

where $\mu_{\text {eff }}\left(\mathrm{m}^{2} \mathrm{~s}^{-1} \mathrm{~V}^{-1}\right)$ is the effective mobility of a particular ion for a given porous material and is given by:

$\mu_{\text {eff }}=\phi T^{*} \mu$,

where $\phi\left(\mathrm{m}^{3} \mathrm{~m}^{-3}\right)$ is the porosity and $T^{*}$ is the tortuosity of the material.

In porous materials the effective ionic mobility $\mu_{\mathrm{eff}}$ is usually estimated by using the Nernst-TownsendEinstein relation [18]:

$\mu_{\mathrm{eff}}=\frac{D_{\mathrm{eff}} Z F}{R T}$,

where $D_{\text {eff }}\left(\mathrm{m}^{2} \mathrm{~s}^{-1}\right)$ is the effective diffusion coefficient of a particular ion for a given porous material, $Z$ is the charge number, $F\left(\mathrm{C} \mathrm{mol}^{-1}\right)$ is the Faraday constant, $R\left(\mathrm{~J} \mathrm{~K}^{-1} \mathrm{~mol}^{-1}\right)$ is the ideal gas constant, and $T(\mathrm{~K})$ is the absolute temperature.

The applied electric field does not only promote the movement of salt ions through the porous material but it also produces new ionic species at the boundaries of the material due to electrochemical reactions at the electrodes. In the case of inert electrodes the following reactions take place:

(Anode side) $\quad 2 \mathrm{H}_{2} \mathrm{O}-4 e^{-} \rightarrow 4 \mathrm{H}^{+}+\mathrm{O}_{2}$

(Cathode side) $\quad 2 \mathrm{H}_{2} \mathrm{O}+2 e^{-} \rightarrow 2 \mathrm{OH}^{-}+\mathrm{H}_{2}$

The relatively higher diffusion coefficients and effective mobilities of hydrogen $\mathrm{H}^{+}$and hydroxyl $\mathrm{OH}^{-}$ions [18] and an increase in their concentration with time can result in lowering the transference number of salt ions and consequently limiting their transport in porous materials. Such a decrease in the transference number of chloride ions under the influence of $\mathrm{OH}^{-}$ions has been observed during their electrochemical removal from the concrete [19]. Moreover, in the case of $\mathrm{pH}$ sensitive materials the acidic environment around the anode in particular can cause damage. 


\subsection{Total mass flux}

The total mass flux of ions through a porous material under the combined effect of diffusion, advection and electromigration, $J$, is given by adding together their respective fluxes [20]:

$J=D_{\mathrm{eff}} \frac{\partial C}{\partial x}+C v_{\mathrm{h}}+\mu_{\mathrm{eff}} C \frac{\partial V}{\partial x}$

The variation in concentration of salt ions with time is obtained by using the law of conservation of mass:

$\frac{\partial C}{\partial t}=-\nabla J$

Hence by combining Eqs. 12 and 13, the variation in concentration is given by:

$\frac{\partial C}{\partial t}=D_{\text {eff }} \frac{\partial^{2} C}{\partial x^{2}}-v_{\mathrm{h}} \frac{\partial C}{\partial x}-\mu_{\text {eff }} \frac{\partial C}{\partial x} \frac{\partial V}{\partial x}$

Here we have assumed that $D_{\text {eff }}$ is independent of salt concentration, $v_{\mathrm{h}}$ is uniform and the variation in electric field (i.e. $(\partial V / \partial x))$ is linear across the specimen.

\section{Experimental}

In order to study the variation in moisture and salt concentration within the brick specimen under the effect of diffusion, advection and electromigration two types of sample holders were designed to be used in the NMR set-up. The detail of both the electrokinetic and NMR set-ups is given below.

\subsection{Electrokinetic set-up}

To obtain information regarding the variation in moisture and salt concentration in the salt contaminated brick specimen during the experiments, two types of sample holders were designed (see in Fig. 1) for use inside the NMR set-up. The specimen used in these sample holders were initially cut in cylindrical shapes of length $6 \mathrm{~cm}$ and diameter $2 \mathrm{~cm}$. After drying in a furnace at $105 \pm 5^{\circ} \mathrm{C}$ for $24 \mathrm{~h}$ these brick specimen were vacuum saturated in a $4 \mathrm{M} \mathrm{NaCl}$ solution. The longitudinal surfaces of the specimens were wrapped in Teflon tape to prevent evaporation while keeping their faces uncovered.

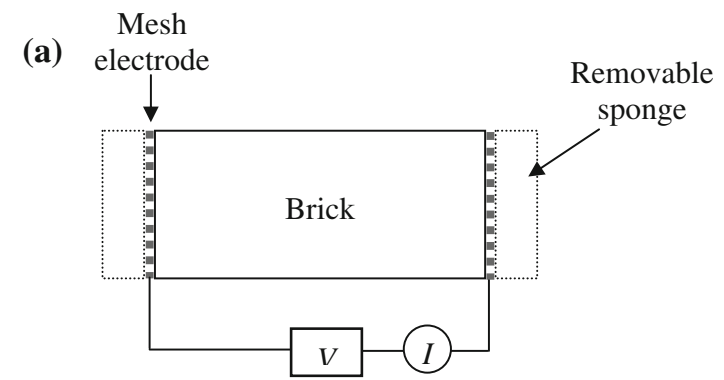

(b)

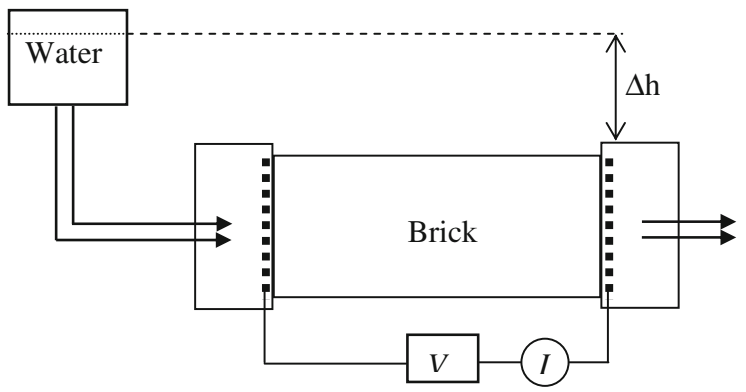

Fig. 1 Schematic diagram of the sample holder used during diffusion and electromigration experiments (a) and during advection and advection-electromigration experiments (b)

In order to study the transport of $\mathrm{Na}$ ions through fired-clay bricks three types of experiments were performed. First, the influence of concentration gradient, i.e. diffusion, on the transport of $\mathrm{Na}$ ions was studied by applying sponges, soaked with demineralized water, to the uncovered faces of the brick. Secondly, the transport of $\mathrm{Na}$ ions under the effect of a hydraulic gradient (i.e. advection) was observed by introducing a constant height difference in the water level of $2 \mathrm{~cm}$ across the sample. The combined effect of both the hydraulic and potential gradients i.e. advection-electromigration on the salt transport was also studied by exposing the specimen to both the potential and hydraulic gradients simultaneously. Thirdly, the effect of the intensity of applied electric field on the migration of $\mathrm{Na}$ ions was studied by using platinum mesh electrodes applied together with the wet sponges across the specimen.

In both diffusion and electromigration experiments the sponges were replaced after measuring each profile (i.e. after $30 \mathrm{~min}$ ) to avoid any back diffusion of salt ions from the sponges to the brick and to suppress any variation in $\mathrm{pH}$ caused by the oxidation and reduction reactions at the anode and cathode respectively. Platinum electrodes were used to avoid 
the introduction of secondary corrosion products. During the electromigration experiments the current I (A) across the brick was continuously monitored and it was observed that it remained approximately constant during the entire experiment with in $\sim 10 \%$.

\subsection{NMR set-up}

NMR technique exploits the magnetic properties of nuclei possessing non-zero magnetic moments. When such nuclei are placed in an externally applied static magnetic field, their magnetic moments precess around the applied field. Depending on the strength of applied magnetic field $B_{0}(\mathrm{~T})$, the resonance frequency or the so-called Larmor frequency $f_{1}(\mathrm{~Hz})$ of these nuclei is given by [21]:

$f_{1}=\frac{\gamma_{i}}{2 \pi} B_{0}$

where the index $i$ refers to the type of nucleus ( $\mathrm{H}$ or $\mathrm{Na}), \gamma_{i}\left(\mathrm{~Hz} \mathrm{~T}^{-1}\right)$ is the gyromagnetic ratio $\left(\gamma_{\mathrm{H}} /\right.$ $2 \pi=42.58 \mathrm{MHz} \mathrm{T}^{-1} ; \quad \gamma_{\mathrm{Na}} / 2 \pi=11.27 \mathrm{MHz} \mathrm{T}^{-1}$ ) which has a unique value for each nuclei.

The NMR measurements reported in this article were performed using the so-called spin-echo technique [22]. The magnitude of NMR spin-echo signal is given by [21]:

$S \propto \alpha \rho\left[1-\exp \left(-t_{\mathrm{r}} / t_{1}\right)\right] \exp \left(-t_{\mathrm{e}} / t_{2}\right)$

where $\alpha$ is the relative sensitivity of particular nuclei in comparison with hydrogen $(\alpha=0.093$ for $\mathrm{Na})$, $\rho\left(\mathrm{mol} \mathrm{l}^{-1}\right)$ the density of nuclei under investigation,

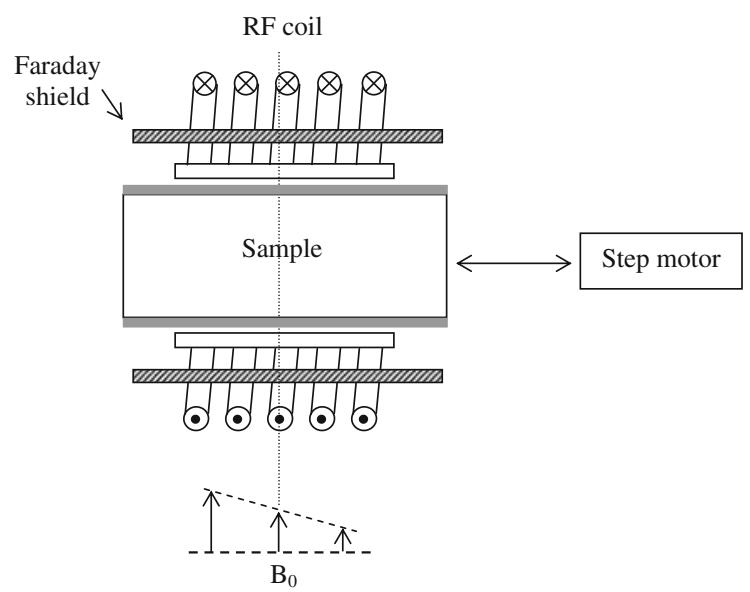

Fig. 2 A schematic diagram of the NMR set-up for measuring the moisture and $\mathrm{Na}$ during desalination experiments

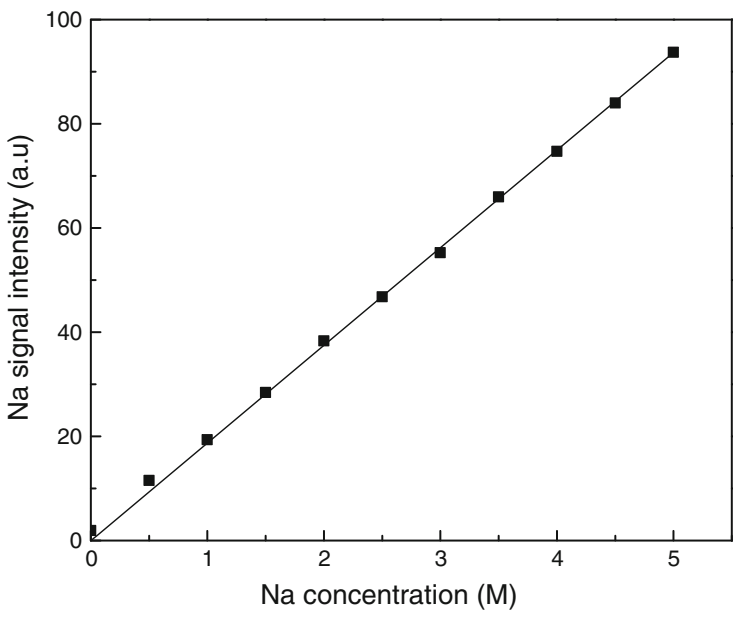

Fig. 3 Variation in $\mathrm{Na}$ signal intensity as a function of $\mathrm{NaCl}$ concentration within the fired-clay brick

$t_{1}$ (s) the spin-lattice (longitudinal) relaxation time, $t_{\mathrm{r}}(\mathrm{s})$ the repetition time of the spin-echo experiment, $t_{2}$ (s) the spin-spin (transverse) relaxation time, and $t_{\mathrm{e}}$ (s) the spin-echo time.

For the experiments described in this article a home-built NMR set-up was used. The schematic diagram of the NMR set-up is shown in Fig. 2.

This NMR set up uses conventional electromagnets that produce magnetic field of $0.96 \mathrm{~T}$. In order to measure quasi-simultaneously both the hydrogen and $\mathrm{Na}$ profiles during the desalination treatment, a specially designed RF circuit was incorporated [13]. A constant magnetic field gradient of $0.1 \mathrm{~T} \mathrm{~m}^{-1}$ was applied using Anderson coils, giving a one-dimensional spatial resolution of 1 and $4 \mathrm{~mm}$ for the hydrogen and $\mathrm{Na}$ respectively. First the moisture content in the small region of the sample near the centre of the RF coil is measured. Next the frequency is changed from $\mathrm{H}$ to $\mathrm{Na}$ and the $\mathrm{Na}$ content in that region is measured. After these two measurements the sample is moved in the horizontal direction and the moisture and $\mathrm{Na}$ contents are measured. This procedure is repeated until complete moisture and $\mathrm{Na}$ profile is measured.

In order to relate the variation in NMR signal intensities with the variation in $\mathrm{Na}$ concentration the calibration was performed on fired-clay brick before starting the experiments. A linear variation in $\mathrm{Na}$ signal intensity with the $\mathrm{NaCl}$ concentration, as is shown in Fig. 3, indicates that no adsorption of $\mathrm{Na}$ ions is taking place at the pore surfaces and as it is 

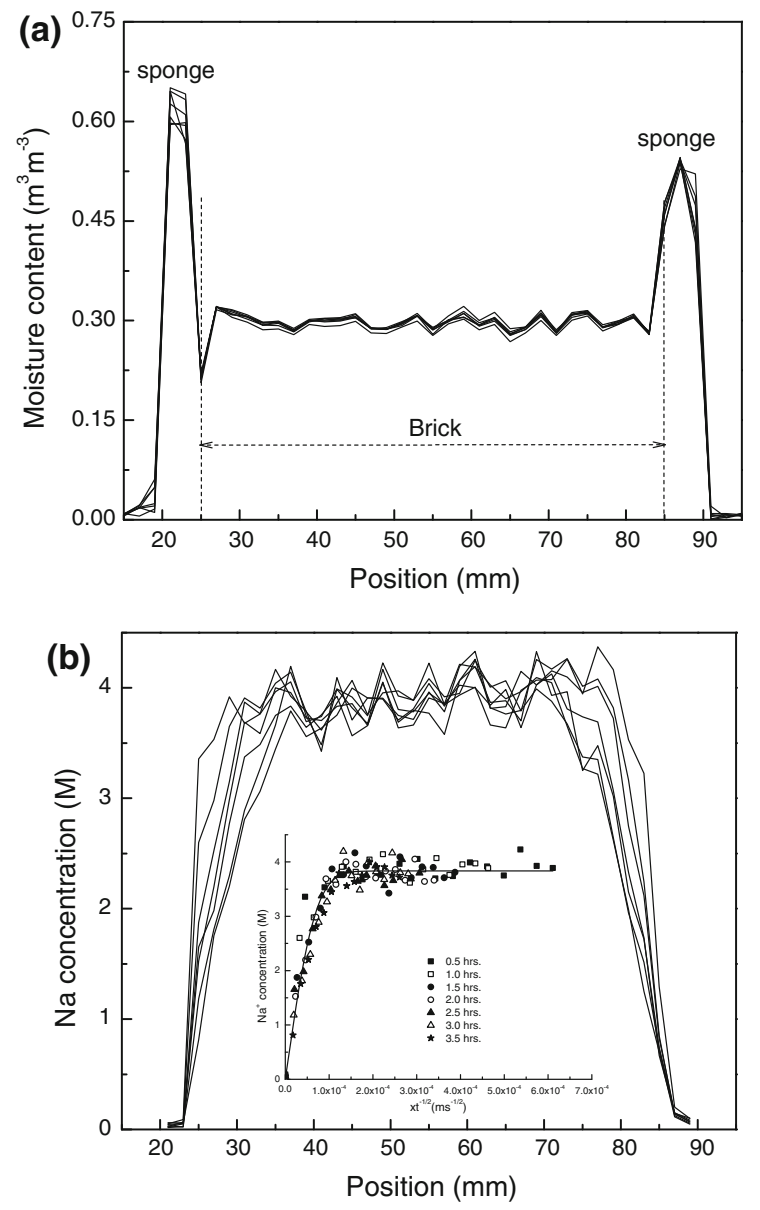

Fig. 4 a Moisture and $\mathbf{b} \mathrm{Na}$ concentration profiles in the firedclay brick during the diffusion experiment including transformed profiles in the inset. The measurement time for each profile is $30 \mathrm{~min}$

already reported by Pel et al. [23] the fired-clay bricks behave as inert materials. The variation in $\mathrm{Na}$ concentration profiles presented in the following section are calibrated by the $\mathrm{Na}$ signal intensity curve as shown in Fig. 3.

\section{Results and discussion}

\subsection{Diffusion experiment}

The moisture and $\mathrm{Na}$ concentration profiles measured during the diffusion experiment are given in Fig. 4, in which the fired-clay brick is located between the vertical dashed lines. The lack of change in the moisture content of brick (Fig. 4a) indicates that drying did not take place during the entire experiment. The sharp peaks at both ends of the sample in Fig. 4a indicate the location of the sponges.

In the absence of drying the symmetry of $\mathrm{Na}$ concentration profiles indicates that the brick specimen is homogenous and due to diffusion an equal amount of salt is removed from both sides of the brick. In order to verify that diffusion is the only transport process involved in salt transport the Boltzmann-Matano transformation $\lambda=x / t^{1 / 2}$ [24] was performed on both the left and right halves of the measured $\mathrm{Na}$ concentration profiles separately. The collapse of $\mathrm{Na}$ concentration profiles into a single master curve after the transformation confirmed that the transport of salt ions from both ends of the brick to the sponges is taking place due to diffusion. The Na concentration profiles from the left half of the brick after the BoltzmannMatano transformation are shown in the inset of Fig. 4b. As it can be seen in the inset of Fig. $4 b$ that the $\mathrm{Na}$ concentration profiles data after the transformation is fitted well by the solid curve obtained by using the error function:

$C=C_{0} \operatorname{erf} \frac{\lambda}{2 \sqrt{D_{\text {eff }}}}$

with the following initial and boundary conditions:

$$
\begin{aligned}
& C=C_{0}, \text { at } \lambda>0, t=0 \\
& C=0, \text { at } \lambda=0 \text { and } C=C_{0}, \\
& \quad \text { at } \lambda \rightarrow \infty, \text { for all time } t>0
\end{aligned}
$$

where $C_{0}\left(\mathrm{~mol} \mathrm{l}^{-1}\right)$ is the initial $\mathrm{Na}$ concentration within the brick.

By using the above given initial and boundary conditions in Eq. 17 the diffusion coefficient of $\mathrm{Na}$ ions in the brick of the order of $0.80 \times 10^{-9} \mathrm{~m}^{2} \mathrm{~s}^{-1}$ is obtained by curve fitting and is in good agreement with the reported values [15].

\subsection{Advection experiment}

The Na concentration profiles measured by maintaining a water level height difference of $2 \mathrm{~cm}$ across the salt contaminated brick specimen are shown in Fig. 5a. The profiles indicate a clear movement of $\mathrm{Na}$ ions from the left (higher water level) to the right (lower water level) side of the brick. The variation in position of the $\mathrm{Na}$ front (at the concentration level of $2 \mathrm{M})$ with time is linear and is shown in Fig. $5 \mathrm{~b}$. 

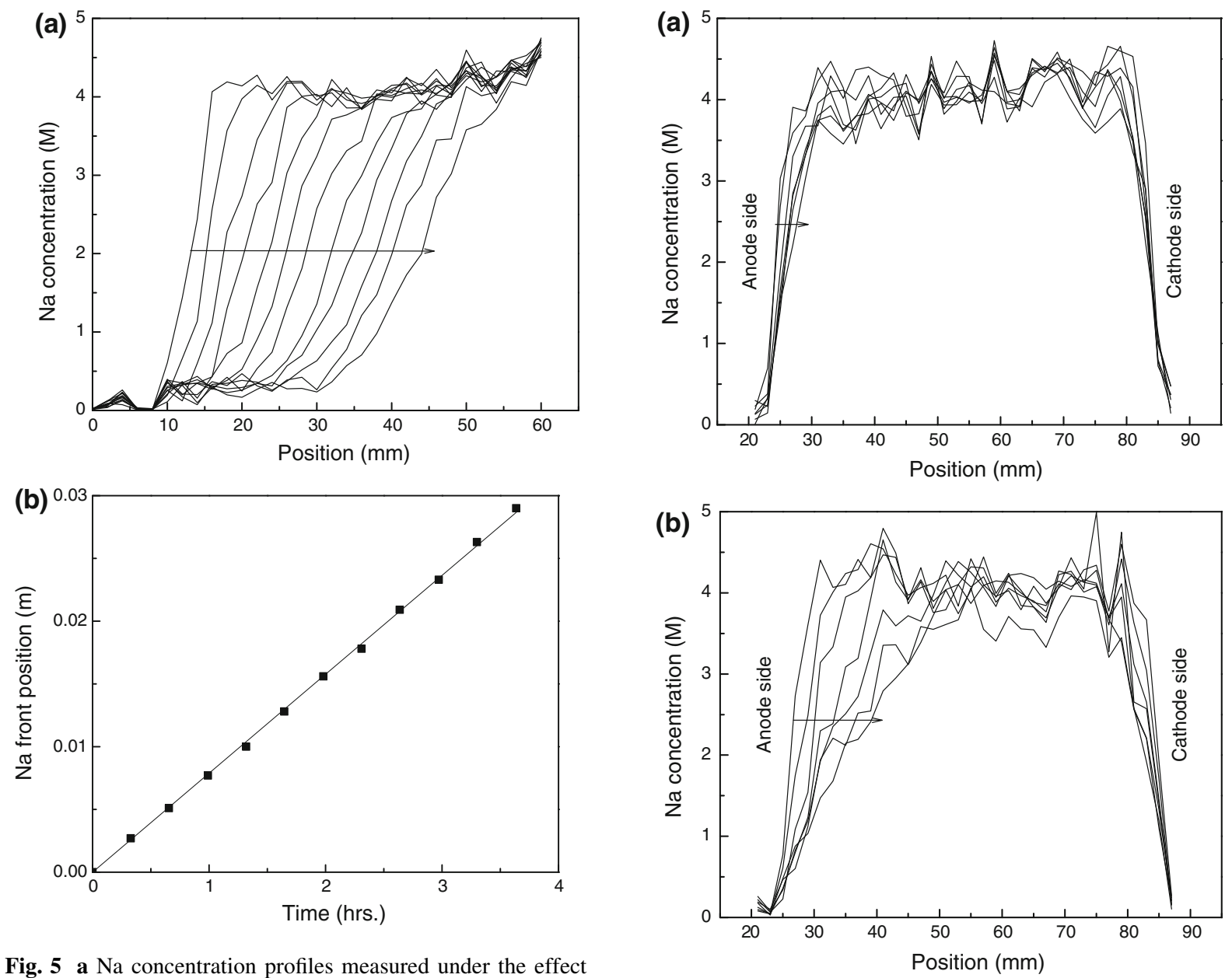

Fig. 5 a Na concentration profiles measured under the effect of advection by introducing a water level height difference of $2 \mathrm{~cm}$. b The variation in position of $\mathrm{Na}$ front with time. The $\mathrm{Na}$ front position is taken approximately where the arrow is intersecting the $\mathrm{Na}$ profiles in a. The measurement time for each profile is $18 \mathrm{~min}$

From the slope of the linear fit the $\mathrm{Na}$ front speed of $2.20 \times 10^{-6} \mathrm{~m} \mathrm{~s}^{-1}$ was obtained.

By taking this value for the speed of the $\mathrm{Na}$ front as the volumetric flux, i.e. $v_{\mathrm{h}}$, and using it in Eq. 4 the intrinsic permeability of the fired-clay brick used in this experiment, of the order of $6 \times 10^{-13} \mathrm{~m}^{2}$, was obtained and it is comparable to the permeability value of $10^{-12} \mathrm{~m}^{2}$ as reported by van der Heijden et al. [17].

\subsection{Electromigration experiments}

The influence of the applied electric field on the migration of $\mathrm{Na}$ ions was studied by applying potential gradients ranging from $0.75-2 \mathrm{~V} \mathrm{~cm}^{-1}$ across the specimen. Note that the actual potential gradient across

Fig. $6 \mathrm{Na}$ concentration profiles during application of potential gradients: a $0.75 \mathrm{~V} \mathrm{~cm}^{-1}$ and $\mathbf{b} 1.58 \mathrm{~V} \mathrm{~cm}^{-1}$. The arrows indicate the direction of the $\mathrm{Na}$ front as it moves from the anode deeper inside the brick towards the cathode. The measurement time for each profile is $30 \mathrm{~min}$

the specimen is smaller than the applied gradient due to polarization of the electrodes. The measured $\mathrm{Na}$ concentration profiles under the applied potential gradients of 0.75 and $1.58 \mathrm{~V} \mathrm{~cm}^{-1}$ are shown in Fig. 6. It can be seen that the symmetry in the $\mathrm{Na}$ concentration profiles, which was observed during the diffusion experiment (Fig. 4b), is lost. A clear $\mathrm{Na}$ front profile is observed moving through the sample from the anode to the cathode, indicating that $\mathrm{Na}$ ions are moving towards the cathode. In the case of $1.58 \mathrm{~V} \mathrm{~cm}^{-1}$ the progression of $\mathrm{Na}$ front is much faster than at $0.75 \mathrm{~V} \mathrm{~cm}^{-1}$.

The position of $\mathrm{Na}$ front under applied field strengths (from $0.75-2 \mathrm{~V} \mathrm{~cm}^{-1}$ ) is shown in Fig. 7a. 

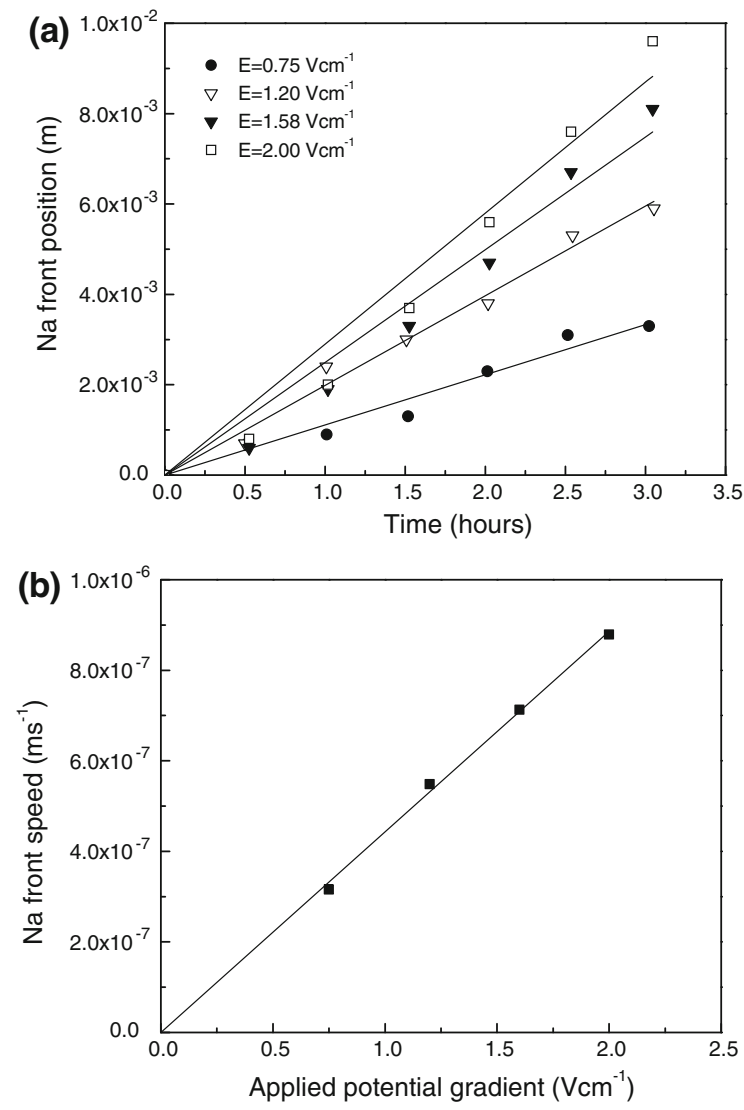

Fig. 7 a Variation in the position of $\mathrm{Na}$ front as a function of time. b Average speed of $\mathrm{Na}$ front as a function of applied potential gradients

In all cases a linear increase in the position of $\mathrm{Na}$ front with time indicates a constant speed of the $\mathrm{Na}$ front. The $\mathrm{Na}$ front speed as a function of the applied potential gradients is given in Fig. $7 \mathrm{~b}$.

From the slope of linear fit (Fig. 7b) the effective mobility $\left(\mu_{\text {eff }}\right)$ of the Na ions obtained is of the order of $4.43 \times 10^{-9} \mathrm{~m}^{2} \mathrm{~s}^{-1} \mathrm{~V}^{-1}$. However, this value is lower than the mobility derived from the diffusion experiment according to Eq. 9; which equals to $32 \times 10^{-9} \mathrm{~m}^{2} \mathrm{~s}^{-1}$. This difference in mobilities might be attributed to the fact the actual potential gradients across the sample are smaller than the applied potential gradients due to polarization of electrodes.

\subsection{Diffusion versus advection and electromigration}

A comparison between each of the transport processes i.e. diffusion, advection and electromigration is made

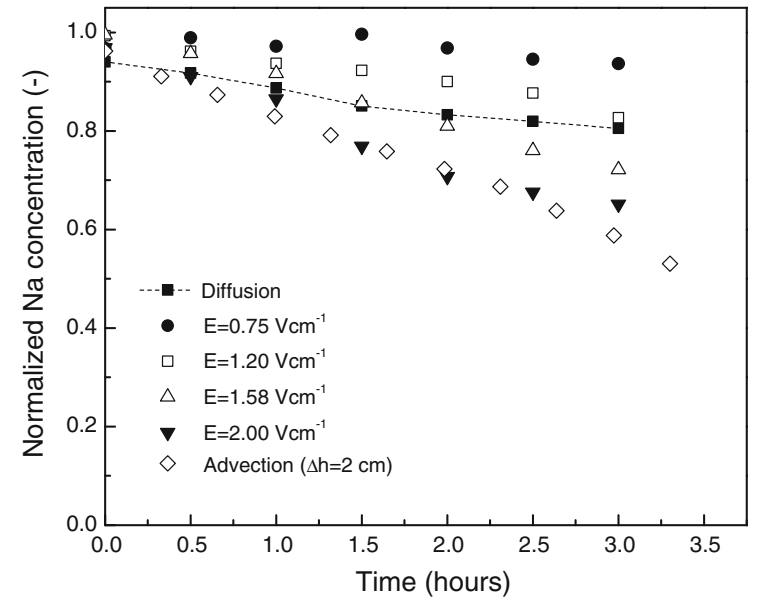

Fig. 8 The variation in normalized Na concentration with time under the effect of diffusion, advection and electromigration at different applied field strengths. Above the dashed line $\mathrm{Na}$ transport is dominated by diffusion and below this line by electromigration and advection

by taking into account their respective contribution in the reduction of $\mathrm{Na}$ concentration in fired-clay brick during the entire experiment. The variation in normalized $\mathrm{Na}$ concentration in the brick during diffusion, advection $(\Delta \mathrm{h}=2 \mathrm{~cm})$, and electromigration at different applied field strengths (from 0.75 to $2 \mathrm{~V} \mathrm{~cm}^{-1}$ ) is shown in Fig. 8. The normalization was performed by integrating the $\mathrm{Na}$ concentration of each measured profile over the entire brick and then dividing it with the integrated $\mathrm{Na}$ concentration profile of the same brick measured just before the start of experiment.

It can be seen that within the time scale of the experiments and the length of the specimen used, up to applied field strength of $1.20 \mathrm{~V} \mathrm{~cm}^{-1}$ diffusion is dominant over electromigration. At applied field strengths of 1.58 and $2 \mathrm{~V} \mathrm{~cm}^{-1}$ electromigration dominates the transport process. However, in these experiments advection was shown to be dominant over both diffusion and electromigration.

The results presented in Fig. 8 shows that, in comparison with diffusion and electromigration, salts can be efficiently removed by hydraulic advection from relatively high permeable materials like firedclay bricks. However, the in situ removal of salts by hydraulic advection from building structures has severe limitations. Even in the case of very simple building structures made up of relatively high permeable materials i.e. fired-clay bricks it is difficult to expose the entire building to a hydraulic gradient. 
In order to overcome these difficulties the injection-poultice technique has been developed for in situ use in the brickwork [3] where salt transport is accomplished by advection. In this method water is injected through deep holes bored into the joints of wall and the salt contaminated water is sucked back from the same side of the wall to the sponges either by capillary pressure due to drying or by pumping water using the pumps at the adjacent outer layer of the wall.

However, in the case of low permeable building materials e.g. mortar and concrete the salt transport by hydraulic advection is practically impossible due to extremely high hydraulic gradients requirement. In this type of materials electromigration is amongst the possible ways to accomplish salt extraction.

\subsection{Scale analysis of transport processes}

The results presented in the previous subsections show that all the transport processes i.e. diffusion, advection and electromigration can have significant effect on the transport of salt ions through fired-clay bricks. The dominance of any particular transport process can be determined by undertaking a scale analysis. The scale analysis regarding competition between diffusion-advection and diffusion-migration is made on the basis of Peclet number, Pe, defined as the ratio between the rates of transport by convection to the molecular diffusion [25]. In this study the $P e$ has been used to determine the competition between the processes that lead to directional mass transport (i.e. advection and electromigration) to the random mass transport i.e. diffusion. In the case of advectionelectromigration, where both the processes lead to a directional mass transport, the scale analysis is made by introducing a new dimensionless number, $\xi$. In this analysis the characteristic length is the length of the specimen (i.e. $6 \mathrm{~cm}$ ) that was used during the experiments.

\subsubsection{Diffusion versus advection}

In the case of diffusion-advection the competition between these transport processes is characterized by using the Peclet number, Pe, obtained by making dimensional analysis of Eq. 14:
$P e=\frac{\left|v_{\mathrm{h}}\right| L}{D_{\mathrm{eff}}}$

where $v_{\mathrm{h}}$ denotes the velocity of solute i.e. the $\mathrm{Na}$ ions, $D_{\text {eff }}$ is the effective diffusion coefficient of the ions and $L(\mathrm{~m})$ is the length of the specimen used in the experiment. If $P e \gg 1$, then the transport of salt ions through the porous material is dominated by the hydraulic advection. For diffusion to be dominant over hydraulic advection the Peclet number must be less than one (i.e. $P e \ll 1$ ).

The competition between diffusion and advection can also be characterized by using Peclect number based on the time scales for both the transport processes and is given by:

$P e=\frac{L^{2} / D_{\text {eff }}}{L / \nu_{\mathrm{h}}}=\frac{\tau_{\text {diffusion }}}{\tau_{\text {advection }}}$

where $\tau_{\text {diffusion }}(\mathrm{s})$ is the diffusion time and $\tau_{\text {advection }}(\mathrm{s})$ is the time for hydraulic advection. By using $D_{\text {eff }}=0.80 \times 10^{-9} \mathrm{~m}^{2} \mathrm{~s}^{-1}$ as the diffusion coefficient as determined by diffusion experiment and $v_{\mathrm{h}}=2.20 \times 10^{-6} \mathrm{~m} \mathrm{~s}^{-1}$ as the velocity of $\mathrm{Na}$ ions through the brick that was obtained during advection experiment, the Peclet number thus obtained is given by:

$P e=\frac{\tau_{\text {diffusion }}}{\tau_{\text {advection }}}=165$

This means that for a height difference of $2 \mathrm{~cm}$ the advection is dominant over diffusion and it is in agreement with the experimental results.

For diffusion to be in equilibrium with advection i.e. for $P e=1, v_{\mathrm{h}}$ should be equal to $1.32 \times 10^{-8} \mathrm{~m} \mathrm{~s}^{-1}$, which corresponds to height difference of less than $0.13 \mathrm{~mm}$. In order for diffusion to dominate over advection, i.e. for $P e \ll 1$, the difference in water level across the brick should be much less than $0.1 \mathrm{~mm}$.

At first such a significant effect on salt transport due to a relatively low pressure difference of 200 Pa caused by a $2 \mathrm{~cm}$ height difference across the fired-clay bricks seems to be unrealistic. However, depending on the permeability of materials even in the presence of extremely small pressure differences, as it is shown in the calculation for Peclet number, advection can dominate the diffusion transport. Poupeleer et al. [26] while performing diffusion experiments noted that the density differences in liquid in response to the variation in salt concentration in different compartments of a diffusion cell produced enough hydrostatic pressure 
differences across a ceramic brick to make advection a dominant transport mechanism.

\subsubsection{Diffusion versus electromigration}

From Eq. 14, the competition between diffusion and electromigration on salt transport can also be characterized by using a Peclet number:

$P e=\left|\frac{\mu_{\mathrm{eff}} V}{D_{\mathrm{eff}}}\right|$

In the case of using Eq. 23, if $P e \gg 1$, then electromigration will dominate, while for $P e \ll 1$ diffusion dominates. In terms of the time scales for both diffusion and electromigration the Peclect number is given by:

$P e=\frac{L^{2} / D_{\text {eff }}}{L^{2} / \mu_{\text {eff }} V}=\frac{\tau_{\text {diffusion }}}{\tau_{\text {migration }}}$

In this case if $P e \ll 1$ then diffusion will dominate over electromigration and vice versa. The time $\tau_{\text {diffusion }}$ taken by diffusion to desalinate a specimen of $6 \mathrm{~cm}$ length is of the order of $4.5 \times 10^{6} \mathrm{~s}$. Conversely, the maximum time $\tau_{\text {migration }}$ that corresponds to a $0.75 \mathrm{~V} \mathrm{~cm}^{-1}$ potential gradient is of the order of $2 \times 10^{5} \mathrm{~s}$. Thus, according to Eq. 24 electromigration will be dominant during all the applied potential gradients $\left(0.75-2 \mathrm{~V} \mathrm{~cm}^{-1}\right)$. However, according to the experimental results (Fig. 8) electromigration dominates over diffusion after a potential gradient of $1.20 \mathrm{~V} \mathrm{~cm}^{-1}$ is applied.

\subsubsection{Advection versus electromigration}

In the case of advection-electromigration transport the dimensionless number $\xi$ obtained from the dimensional analysis of Eq. 14 is:

$\xi=\left|\frac{\mu_{\mathrm{eff}} V}{v_{\mathrm{h}} L}\right|$

The competition between advection and electromigration on salt transport in terms of $\xi$ based on their time scales can be written as:

$\xi=\frac{L / v_{\mathrm{h}}}{L^{2} / \mu_{\mathrm{eff}} V}$

By using the Na velocity $v_{\mathrm{h}}=2.20 \times 10^{-6} \mathrm{~m} \mathrm{~s}^{-1}$ and $\mu_{\text {eff }}=4.43 \times 10^{-9} \mathrm{~m}^{2} \mathrm{~s}^{-1} \mathrm{~V}^{-1}$ in Eq. 26, depending on the value of applied voltage, $\xi$ lies
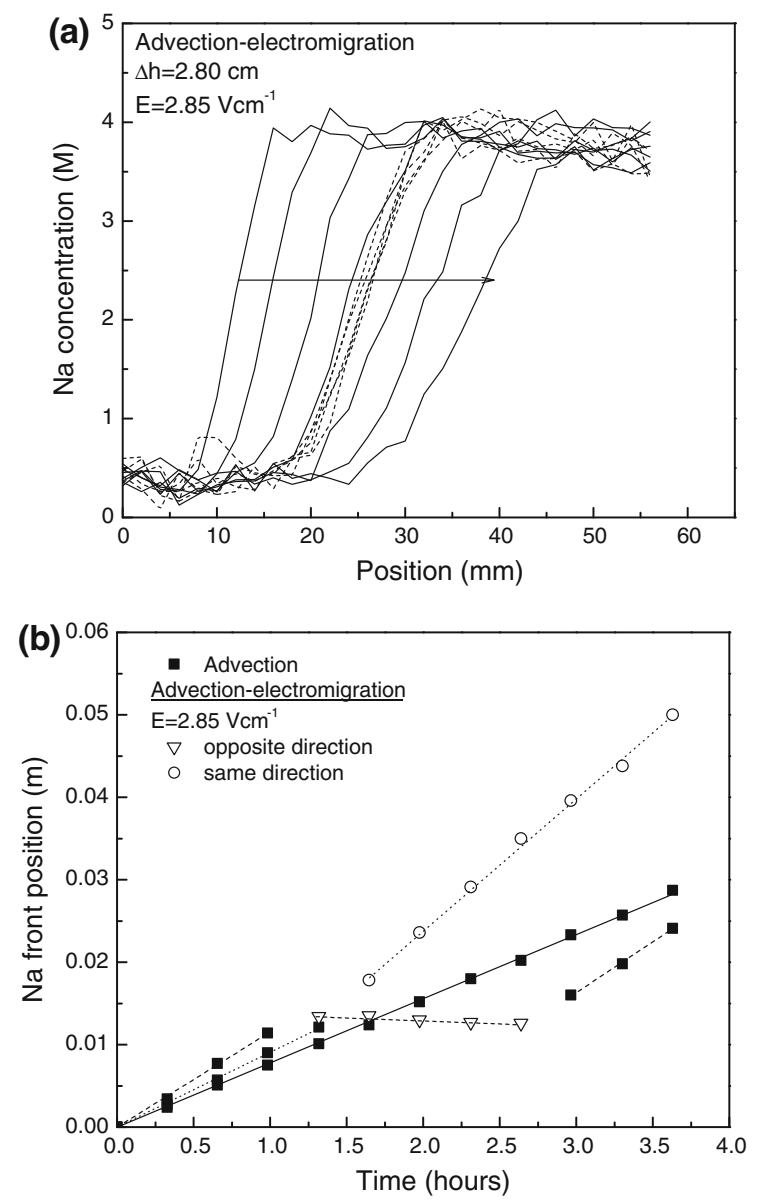

Fig. 9 a Na concentration profiles represented by solid lines indicate the movement of $\mathrm{Na}$ ions through the brick under the effect of advection. The dashed lines show the Na profiles when both the hydraulic and field gradients were simultaneously applied in opposite direction to each other. b The variation in the position of $\mathrm{Na}$ front under the effect of only hydraulic gradient (i.e. advection) and under the simultaneous effect of both hydraulic and potential gradients applied in the opposite and in the same directions to each other. The measurement time for each profile is $18 \mathrm{~min}$

between 0.1 and 0.4 . These values suggest that both the advection and electromigration are comparable with each other. Therefore, it is possible to halt the transport of salt ions due to advection by applying a potential gradient in the opposite direction to that of advection.

This effect was experimentally verified when a potential gradient was applied in opposite direction to that of the movement of $\mathrm{Na}$ ions due to hydraulic gradient across the specimen and is shown in Fig. 9a. The $\mathrm{Na}$ concentration profiles shown by solid line 
represent the movement of $\mathrm{Na}$ ions due to hydraulic gradient by maintaining a height difference of $2.80 \mathrm{~cm}$ across the specimen. The effect of potential gradient of $2.85 \mathrm{~V} \mathrm{~cm}^{-1}$ applied in opposite to hydraulic gradient is represented by the dashed lines.

The corresponding $\mathrm{Na}$ front positions when the hydraulic and potential gradients are applied in opposite directions are represented by open triangles as shown in Fig. 9b. This figure also includes the front position of $\mathrm{Na}$ when hydraulic and potential gradients are applied in the same direction (open circles) and when only hydraulic gradient is applied (solid squares). In the case of only advection same results are again used that have already been presented in Fig. 5b. For both the advection-electromigration experiments the data represented by solid squares represent the position of $\mathrm{Na}$ front when no electric field was applied across the specimen. Although the removal of $\mathrm{Cl}$ ions is also important as they are responsible for the corrosion of e.g. reinforcements in concrete but the present study is limited to Na ions as in our NMR setup the sensitivity for $\mathrm{Cl}$ is too low.

\section{Conclusions}

It is possible to measure the transport of $\mathrm{Na}$ ions during electrokinetic desalination non-destructively using NMR. In the case of electromigration the salt ( $\mathrm{Na}$ ions) removal rate is proportional to the applied electric field across the non-reactive porous materials. For electromigration to be dominant over diffusion a minimum level of electric field is necessary. Below this threshold electric field, diffusion is dominant over electromigration. Salt ( $\mathrm{Na}$ ions) transport by advection is quite significant in the case of fired-clay bricks. The transport of $\mathrm{Na}$ ions can be enhanced if hydraulic and potential gradients are applied in the same direction, but if applied in opposing directions the rate of salt ( $\mathrm{Na}$ ions) removal can be reduced or completely halted.

The results presented in this article and the conclusions drawn are based on relatively short term measurements (i.e. up to three and half hours). Moreover, the transport of salt ions only for one type of building materials i.e. fired-clay brick has been studied. In order to get better understanding about the role played by diffusion, advection and electromigration on the ionic transport the long term measurements on different types of porous building materials will be part of the future study.

Acknowledgments Thanks are due to Hans Dalderop and Jef Noijen for providing technical assistance, and also to Gijs van der Heijden for much useful discussion. We are grateful to the Higher Education Commission, Pakistan and Nuffic, the Netherlands for their financial support and administrative assistance during this project.

Open Access This article is distributed under the terms of the Creative Commons Attribution Noncommercial License which permits any noncommercial use, distribution, and reproduction in any medium, provided the original author(s) and source are credited.

\section{References}

1. Auras M (2008) Salt weathering on buildings and stone sculptures. In: Proceedings from the international conference, 22-24 Oct 2008, Technical University of Denmark, The National Museum Copenhagen, Copenhagen

2. Sawdy A, Heritage A, Pel L (2008) Salt weathering on buildings and stone sculptures. In: Proceedings from the international conference, 22-24 Oct 2008, Technical University of Denmark, The National Museum Copenhagen, Copenhagen

3. Verges-Belmin V, Siedel H (2005) Desalination of masonries and monumental sculptures by poulticing: a review. Restor Build Monum 11(6):1-18

4. Pel L, Sawdy A, Voronina V (2010) Physical principles and efficiency of salt extraction by poulticing. J Cult Heritage 11(1):59-67. doi:10.1016/j.culher.2009.03.007

5. Sawdy A, Lubelli B, Voronina V, Pel L (2010) Optimizing the extraction of soluble salts from porous materials by poultices. Stud Conserv 55(1):26-40

6. Ottosen LM, Pedersen AJ, Rorig-Dalgaard I (2007) Salt related problems in brick masonry and electrokinetic removal of salts. J Build Apprais 3(3):181-194

7. Puri AN, Anand B (1936) Reclamation of alkali soils by electrodialysis. Soil Sci 42:23-27

8. Bertolini L, Yu SW, Page CL (1996) Effects of electrochemical chloride extraction on chemical and mechanical properties of hydrated cement paste. Adv Cem Res 8(31):93-100

9. Bertolini L, Coppola L, Gastaldi M, Redaelli E (2009) Electroosmotic transport in porous construction materials and dehumidification of masonry. Constr Build Mater 23(1):254-263. doi:10.1016/j.conbuildmat.2007.12.013

10. Ottosen LM, Rorig-Dalgard I (2007) Electrokinetic removal of $\mathrm{Ca}\left(\mathrm{NO}_{3}\right)_{2}$ from bricks to avoid salt-induced decay. Electrochim Acta 52(10):3454-3463. doi:10.1016/ j.electacta.2006.03.118

11. Ottosen LM, Rorig-Dalgaard I (2009) Desalination of a brick by application of an electric DC field. Mater Struct 42(7):961-971. doi:10.1617/s11527-008-9435-1 
12. Ottosen LM, Ferreira CMD, Christensen IV (2010) Electrokinetic desalination of glazed ceramic tiles. J Appl Electrochem 40(6):1161-1171. doi:10.1007/s10800-0100086-X

13. Pel L, Kopinga K, Kaasschieter EF (2000) Saline absorption in calcium-silicate brick observed by NMR scanning. J Phys D Appl Phys 33(11):1380-1385

14. Atkins P, de Paula J (2002) Atikin's physical chemistry. Oxford University Press, London

15. Ahl J (2004) Salt diffusion in brick structures-Part IIThe effect of temperature, concentration and salt. J Mater Sci 39(13):4247-4254

16. Hall C, Hoff D (2002) Water transport in brick, stone and concrete. Spon Press, London

17. van der Heijden GHA, Bijnen RMW, Pel L, Huinink HP (2007) Moisture transport in heated concrete, as studied by NMR, and its consequences for fire spalling. Cem Concr Res 37(6):894-901. doi:10.1016/j.cemconres.2007.03.004

18. Acar YB, Alshawabkeh AN (1993) Principles of electrokinetic remediation. Environ Sci Technol 27(13): 2638-2647

19. Castellote M, Andrade C, Alonso C (2000) Electrochemical removal of chlorides-modelling of the extraction, resulting profiles and determination of the efficient time of treatment. Cem Concr Res 30(4):615-621

20. Andrade C (1993) Calculation of chloride diffusion-coefficients in concrete from ionic migration measurements. Cem Concr Res 23(3):724-742

21. Abragam A (1961) The principles of nuclear magnetism. Oxford, Clarendon

22. Hahn EL (1950) Spin echos. Phys Rev 80(4):580-594

23. Pel L, Huinink H, Kopinga K (2002) Ion transport and crystallization in inorganic building materials as studied by nuclear magnetic resonance. Appl Phys Lett 81(15): 2893-2895. doi:10.1063/1.1512329

24. Matano C (1932) On the relation between the diffusioncoefficients and concentrations of solid metals (the nickelcopper system). Jpn J Phys 8:109-113

25. Bear J (1988) Dynamics of fluids in porous media. Dover, New York

26. Poupeleer AS, Carmeliet J, Roels S, Van Gemert D (2003) Validation of the salt diffusion coefficient in porous materials. Int J Restor Build Monum 9(6):663-682 